\title{
Virtual APPE grand rounds: A learning activity to enhance remote rotations during the COVID-19 pandemic
}

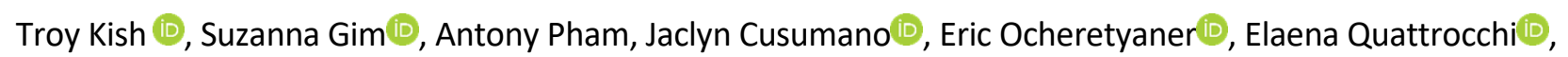 \\ Lana Hareez $(\mathbb{D}$, Mandy Chen, Roda Plakogiannis (D) \\ Arnold and Marie Schwartz College of Pharmacy and Health Sciences (Long Island University), Brooklyn, New York, United States
}

\author{
Keywords \\ Advanced Pharmacy Practice Experience \\ COVID-19 \\ Presentation \\ Remote learning \\ Correspondence \\ Arnold and Marie Schwartz \\ College of Pharmacy and Health Sciences \\ Long Island University \\ Brooklyn \\ New York, United States \\ troy.kish@liu.edu
}

\begin{abstract}
Context: To assess students' perception of a virtual learning activity developed for a remote Advanced Pharmacy Practice Experience (APPE) during the peak of the coronavirus disease 19 (COVID-19) outbreak in New York City. Description of course: Due to the pandemic, many clinical APPEs were converted to remote elective experiences during the final 5-week rotation block (from 1 April to 6 May 2020). A small group of faculty developed and piloted a virtual learning activity (APPE grand rounds) to enhance learning in this setting. Students assigned to participating faculty were tasked to develop 60 to 90-minute presentations scheduled two to three times weekly for large synchronous e-learning experiences across various simultaneous rotations. Evaluation: A questionnaire consisting of nine items utilising a 5-point Likert scale was developed and administered to assess student perception of the virtual format, presentation skills, and overall satisfaction with the experience.
\end{abstract}

\section{Introduction}

E-Learning utilises electronic technologies to administer educational curriculum online and has been used in Doctor of Pharmacy programmes for several years as an enhancement or an alternative means of pedagogic application (Porter et al., 2014, Phillips et al., 2015; Lean et al., 2020). Several studies evaluating Doctor of Pharmacy courses delivered online versus traditional classroom methods have demonstrated overall positive student perception, including statements that online learning was useful, timesaving, enjoyable, and provided a meaningful learning experience (Porter et al., 2014, Phillips et al., 2015; Lean et al., 2020). While the evidence for blended or fully online courses in didactic settings is growing, the utilisation of e-learning in practice-based settings is unclear. Advanced Pharmacy Practice Experiences (APPEs) allow pharmacy students under the supervision of preceptors to be exposed to different pharmacy practice settings for the purpose of applying clinical knowledge and skills for the development of professional competency.

As New York City became the global epicentre for the coronavirus disease 2019 (COVID-19) pandemic in March 2020, the pharmacy programme in Long Island University was faced with several issues, including the sudden prohibition of students in many practice sites, severe reduction or lack of access to routine services such as daycare and mass transit, and widespread concern for the safety for our students and their families, especially given the shortage of available personal protective equipment. Pharmacy programmes and all health profession programmes in the metropolitan area scrambled to convert remaining requirements as necessary to ensure safety while also maintaining on-time graduation as best as possible. The Doctor of pharmacy programme requires students in their final year to complete seven out of nine 5-week rotations during this year. Approximately 50 percent (95 out of 195) of the graduating student pharmacists 
were still required to complete the final 5-week rotation (from 1 April to 6 May 2020) to obtain the degree. Out of the 95 students requiring a final rotation and with careful consideration of the types of rotations required, 45 students were ultimately placed into nonpatient care electives with clinical faculty.

The optimal execution of a completely remote APPE presented a challenge to site-based faculty, as publications on remote or virtual education during APPEs are limited. Al-Dahir and colleagues (2014) published their experience using simulated cases vs faculty-led problem-based learning (PBL) during APPEs. While post-test scores increased following both interventions, students receiving PBL scored higher than those using simulated cases $(74.8 \pm 11.7$ vs $66.5 \pm$ 13.6; $p<0.001)$. Flowers and colleagues (2010) reported that the use of online multimedia vignettes enhanced students' knowledge of patient counselling during a community APPE rotation. Finally, a review by Salter and colleagues (2014) review of E-learning strategies in pharmacy suggests it is effective for increasing student knowledge but recommends additional studies are needed to validate its use. Faced with a purely remote non-patient care APPE, the faculty considered various methods to achieve the Center for the Advancement of Pharmacy Education (CAPE) outcomes 3.2 (Educator) and 3.7 (Communicator) designated in the course syllabus. Several faculty collectively arrived at the creation of virtual APPE grand rounds seminar series. The purpose of this study is to describe our experience with developing virtual grand rounds during remote APPEs and assess student perceptions of this learning activity.

\section{Description of innovation}

A convenience sample of interested faculty of different disciplines (Internal Medicine, Ambulatory Care, and Drug Information) participated in the pilot programme. Each faculty member was assigned two to three students who would participate in the sessions. The organisation of these students was random and aligned with their assignment to different APPE experiences through the Office of Experiential Education. The virtual APPE grand rounds were designed to enhance the remote learning experience as a larger group. Since most rotations require a presentation as an assignment, this activity converted the presentations to a virtual format for an audience, including other participating faculty and students on rotation. Each faculty would have their students present once for the larger group. All participating faculty selected a specific topic and presentation format as well as the date on a master calendar. Each faculty member's group of students would have one presentation scheduled during the 5-week APPE block. Presentations were held 2-3 times weekly and were delivered via a web-based institutional subscribed video conferencing tool (Zoom). Students worked in preceptor-assigned groups to create a 60 to 90 -minute presentation for a large synchronous e-learning experience consisting of faculty, pharmacy residents, and students of the College of Pharmacy. In an effort to maintain the integrity and professionalism of an experiential education rotation, the student participants were required to attend all sessions with their video functionality enabled, and students presenting were expected to wear white lab coats. Preceptors asked students in the audience to prepare questions for the presenting students to increase student involvement and engagement. These questions would be asked at the end of the session, with the presenters providing answers during the session or sending a follow-up email with a complete response in the following days.

The faculty provided guidance and assistance to the students throughout the development of each presentation. Preceptors assisted the students with the selection of a relevant and focused topic, provided feedback on selected literature and the student's critique, and reviewed prepared slides before the presentation date. Presentation formats included simulated case-based topic reviews, general topic reviews, journal club presentations, and pharmacotherapeutic debates. Presentation topics included: simulated patient cases and guideline reviews in community-acquired pneumonia, vancomycin dosing, febrile neutropenia, and type two diabetes mellitus; journal club presentations on COVID-19 and infection management in persons who inject drugs; therapeutic debates on direct oral acting anticoagulation agents and therapeutic management of COVID-19.

To assess student perceptions regarding the Virtual APPE grand rounds, participating faculty developed a questionnaire including nine items utilising a 5-point Likert scale. Three survey items related to the virtual format, four items related to presentation skills, and two items related to overall satisfaction. The questionnaire also included open-ended items to allow for free text feedback and comments. The survey was created on Google Forms (internet-based) and was administered after the last scheduled session via email for voluntary completion to all participating students. Descriptive statistics were used to analyse quantitative survey results and were computed using Microsoft Excel. Qualitative analysis of the open-ended items was performed to identify emerging themes. The university's institutional review board designated this project as exempt. 


\section{Evaluation}

A total of 24 student pharmacists and 11 faculty/ preceptors participated. The ten faculty members were distributed as follows: Drug Information $(n=1)$, Ambulatory Care $(n=3)$, Inpatient clinical pharmacist $(n=7)$, and Pharmacy resident preceptor $(n=1)$, resulting in 11 virtual APPE grand round sessions during the 5 -week period. The number of participants varied between 40 to 50 participants per session.

The results of the survey are summarised in Table I. Only one respondent (out of 24) found the remote format difficult for learning. The majority of students (95.8\%) agreed that the Virtual APPE grand rounds provided an effective format to review clinical topics and disease states. However, only a third of the students agreed that simulated patient cases were as effective as real-life patients (33.4\%). The majority of students $(83.3 \%)$ felt confident presenting in this format, and $87.5 \%$ agreed this experience allowed them to develop their presentation skills and feel more comfortable presenting to a large audience. Most respondents $(70.8 \%)$ agreed that their presentation skills improved with the new virtual format. Two students felt overwhelmed or anxious about the new virtual format (8.4\%). The majority of students (79.2\%) would recommend this rotation to incoming APPE rotation students, and $83.3 \%$ of students agreed that APPE grand rounds should be continued as part of APPEs.

Table I: Virtual APPE grand rounds pilot programme student survey results

\begin{tabular}{|c|c|c|c|c|c|c|}
\hline \multirow{2}{*}{\multicolumn{2}{|c|}{$\begin{array}{l}\text { Survey }(n=24) \\
\text { Statements }\end{array}$}} & \multicolumn{5}{|c|}{ Number of respondents (\%) } \\
\hline & & \multirow{2}{*}{$\begin{array}{l}\text { Strongly } \\
\text { Disagree }\end{array}$} & \multirow[t]{2}{*}{ Disagree } & \multirow[t]{2}{*}{ Neutral } & \multirow[t]{2}{*}{ Agree } & \multirow{2}{*}{$\begin{array}{l}\text { Strongly } \\
\text { Agree }\end{array}$} \\
\hline & & & & & & \\
\hline \multirow{3}{*}{ 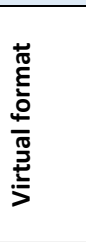 } & $\begin{array}{l}\text { The remote format made it difficult for me to } \\
\text { learn. }\end{array}$ & $8(33.3)$ & $9(37.5)$ & $6(25)$ & $1(4.2)$ & 0 \\
\hline & $\begin{array}{l}\text { This experience provided an effective format for } \\
\text { reviewing clinical topics and disease states. }\end{array}$ & 0 & 0 & $1(4.2)$ & $8(33.3)$ & $15(62.5)$ \\
\hline & $\begin{array}{l}\text { Using simulated patient cases is as effective as } \\
\text { real-life patients. }\end{array}$ & $1(4.2)$ & $5(20.8)$ & $10(41.7)$ & $4(16.7)$ & $4(16.7)$ \\
\hline \multirow{5}{*}{ 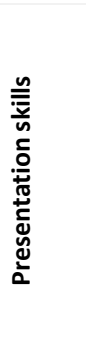 } & This experience allowed me to develop my & 0 & 0 & $3(12.5)$ & $11(45.8)$ & $10(41.7)$ \\
\hline & $\begin{array}{l}\text { presentation skills and feel more comfortable } \\
\text { presenting to a large audience. }\end{array}$ & & & & & \\
\hline & $\begin{array}{l}\text { I was confident with presenting virtually among a } \\
\text { large group of faculty and students. }\end{array}$ & 0 & 0 & $4(16.7)$ & $12(50)$ & $8(33.3)$ \\
\hline & $\begin{array}{l}\text { I feel that my presentation skills improved with } \\
\text { the new virtual format. }\end{array}$ & 0 & $1(4.2)$ & $6(25)$ & $12(50)$ & $5(20.8)$ \\
\hline & $\begin{array}{l}\text { While presenting, I was overwhelmed or anxious } \\
\text { with the new virtual format. }\end{array}$ & $4(16.7)$ & $7(29.2)$ & $11(45.8)$ & $1(4.2)$ & $1(4.2)$ \\
\hline \multirow{2}{*}{ 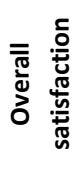 } & $\begin{array}{l}\text { Virtual APPE Grand Rounds should be continued as } \\
\text { part of APPEs. }\end{array}$ & 0 & $1(4.2)$ & $3(12.5)$ & $12(50)$ & $8(33.3)$ \\
\hline & $\begin{array}{l}\text { I would recommend this remote APPE to incoming } \\
\text { final-year students. }\end{array}$ & 0 & $2(8.3)$ & $3(12.5)$ & $12(50)$ & $7(29.2)$ \\
\hline
\end{tabular}

\section{Future work and implementation}

In the setting of the COVID-19 pandemic, the authors were challenged to develop a remote learning experience for the final APPE. The authors developed a virtual APPE grand rounds seminar to deliver a remote group learning experience. Participating students had multiple opportunities to present journal clubs, topic discussions, and patient cases. The majority of participating students provided positive feedback and valued the experience.

The creation of this virtual APPE grand rounds seminar added several new dimensions to a usual group presentation. By allowing faculty and students from different locations to participate, the students were exposed to different perspectives and teaching styles. Presenting to a larger audience of their peers also served as motivation for students to take ownership of the topic while also providing them with additional moral support from their classmates.

This cohort of students required one final APPE rotation to meet the criteria for a doctor of pharmacy degree. As the final APPE, students were able to compare this format with life experiences in previous APPEs. All students had previous opportunities to present journal clubs, topic discussions, and patient cases, which could have influenced their comfort level with participation. 
Students just beginning their APPEs may not feel as comfortable presenting to a large audience and may require more guidance, especially at the beginning of the final year. Additionally, participating students had already completed patient-centred rotations, such as ambulatory care and internal medicine, which may also impact views on using simulated cases compared to students without prior experience. Although polling questions were incorporated in some presentations and all students were required to be virtually on the video screen, audience participation was limited using the virtual format. Additionally, the limited ability to view audience members made it challenging for presenters to gauge audience comprehension, while the virtual format limits the ability to assess traditional presentation skills such as body language and eye contact.

The APPE grand rounds series enables Colleges of Pharmacy to document several components of CAPE Educational Outcomes 3.2 (Educator) and 3.7 (Communicator). With the virtual format, this activity can be incorporated into multiple APPE experiences, which may provide flexibility for the college's curricular mapping. The use of virtual presentations may be of particular interest to smaller colleges where there may only be a single student assigned to a preceptor. These sessions would allow the student to interact and collaborate with their peers in ways they would have been unable to in the past. Digital tools such as Google Docs, Google Slides, or Microsoft Teams could help students to collaborate across different practice sites.

Although preceptors and students agree this learning activity is valuable, continuation after returning to practice sites may be challenging. Potential hurdles at practice sites include difficulties scheduling ambulatory clinic appointments, medical rounds, or increased onsite workloads such as note writing or direct patient care. Technological challenges may include limitations in the technologies permitted at hospital sites, limited access to computers or conference rooms and firewall restrictions on video conferencing. Conversely, the adoption of remote video conferencing has been more widely embraced at many institutions as a part of daily meetings and patient care, allowing for a more friendly infrastructure for this sort of activity to continue. Alternative solutions can include using personal devices such as laptops, smartphones, or tablets to deliver presentations.

Based on written comments provided by students, potential ways to enhance this experience include: providing pre-reading assignments to audience members, developing/administering a tool for formal audience feedback to the presenters, and requiring students in the audience to submit questions. A consideration for future research includes evaluating the impact of inviting students from other professional years of the programme to these sessions. Allowing final year students to serve as role models and demonstrate the expectations for APPEs to underclassmen may influence perceptions of the didactic material. Furthermore, the attendance of students from lower years in the programme may help set both knowledge and performance expectations for their final year.

Limitations to this study findings include that this experience and survey were conducted during the global COVID-19 pandemic. The college and many practice sites are located in New York City, which was the disease epicentre at the time. Levels of stress, uncertainty, and fear may have impacted students' perceptions of learning; thus, students should be surveyed again under more normal circumstances to ensure the validity of our findings.

The COVID-19 pandemic created an urgent situation that prevented standard patient care and student learning. The creation of an APPE grand rounds component to a remote APPE was well-received by participating students. This experience allowed students to engage with a large and more diverse group of peers and faculty than would be attainable if limited to in-person attendance at practice sites. Additionally, the flexibility of presentation type allowed for a wide range of topics to be discussed while also increasing the student's scope of learning and development of presentation skills.

\section{Conclusion}

As colleges brace for the future waves of COVID-19 to disrupt learning, the role of remote education should be considered in the experiential setting. The pilot of a virtual APPE grand rounds seminar presented in this study was well received by students and provided an opportunity to meet curricular outcomes while simultaneously allowing students' education to continue without the need for delays in APPE scheduling. Further exploration of using remote technology during APPEs is warranted.

\section{References}

Al-Dahir, S., Bryant, K., Kennedy, K. B., \& Robinson, D. S. (2014). Online Virtual-Patient Cases Versus Traditional Problem-Based Learning in Advanced Pharmacy Practice Experiences. American Journal of Pharmaceutical Education, 78(4), 76. https://doi.org/10.5688/ajpe78476 
Flowers, S. K., Vanderbush, R. E., Hastings, J. K., \& West, D.

(2010). Web-based Multimedia Vignettes in Advanced Community Pharmacy Practice Experiences. American Journal of Pharmaceutical Education, 74(3), 39. https://doi.org/10.5688/aj740339

Lean QY, Ming LC, Wong YY, Neoh CF, Farooqui M, \& Muhsain SNF. (2020). Online versus classroom learning in pharmacy education: Students' preference and readiness. Pharmacy Education, 20(1),19-27. Available at: https://pharmacyeducation.fip.org/pharmacyeducation/arti cle/view/789

Phillips, J. A. (2015). Replacing traditional live lectures with online learning modules: Effects on learning and student perceptions. Currents in Pharmacy Teaching and Learning, 7(6), 738-744. https://doi.org/10.1016/j.cptl.2015.08.009

Porter, A. L., Pitterle, M. E., \& Hayney, M. S. (2014).

Comparison of Online Versus Classroom Delivery of an Immunization Elective Course. American Journal of Pharmaceutical Education, 78(5), 96.

https://doi/org/10.5688/ajpe78596

Salter, S. M., Karia, A., Sanfilippo, F. M., \& Clifford, R. M. (2014). Effectiveness of E-learning in Pharmacy Education. American Journal of Pharmaceutical Education, 78(4), 83. https://doi.org/10.5688/ajpe78483 